\title{
KAJIAN NAUNGAN, TARAF PUPUK UREA DAN VARIETAS KEDELAI (Glycine $\max$ L.) TERHADAP PERTUMBUHAN DAN PRODUKSI TANAMAN KEDELAI SEBAGAI TANAMAN SELA DI AREAL PERTANAMAN KELAPA SAWIT MENGHASILKAN
}

\section{(The Analysis of Effect of Shading, Urea Dosage and Soybean Variety (Glycine max 1.) on Growth and Yield Performance of Soybean Under Mature Oilpam)}

\author{
Napitupulu Asima ${ }^{1 *}$, Rosmayati ${ }^{2}$, dan Siregar Luthfi Aziz Mahmud ${ }^{2}$ \\ 1) Kementerian Pertanian Jakarta, Indonesia \\ 2, Program Studi Magister Agroekoteknologi, Fakultas Pertanian USU, Medan 20155, Indonesia \\ Corresponding author : ditsayurdaun@gmail.com
}

\begin{abstract}
The aims of this research was to analyze morpo_physiology changing of soybean under oilpam area; determine effect of shading and $\mathrm{N}$ fertilizer dosage on the growth and yield of soybean under oilpam area; and determine suitable soybean varieties that enable grow and produce under oilpalm.The experiment located in Ujung Labuan Village, Deli Serdang District. The experiment was arranged in Split-split Plot Design 3 x 4 x 3 with 3 replication, with three factors observed: 1) shade level, consist of: under 4 years old oilpam, under 6 years old oilpam, open area, 2) N dosage,: $200 \mathrm{~kg}$ urea/ha, $150 \mathrm{~kg} / \mathrm{ha}$, $100 \mathrm{~kg}$ urea/ha, $0 \mathrm{~kg}$ urea/ha, 3) soybean variety: Anjasmoro, Burangrang, and Grobogan. Plant height, leaf area, plant dry weight, and soybean production were determined. Result showed there were some significant effects of interaction factors between oilpalm canopy shading, $\mathrm{N}$ dosage and soybean variety on growth and yield of soybean. The highest growth and production of soybean found at open area. Between 4 years old oilpam and 6-7 years old oilpam, soybean growth and production are unsignificant different, and lower than those on opening area. $\mathrm{N}$ dosage make some significat effects on growth and yield of soybean, which is usually nonsignificant between $150 \mathrm{~kg}$ Urea/ha or $200 \mathrm{~kg}$ Urea/ha. Meanwhile soybean variety make some significat effects. At open area, burangrang make the highest growth and production by application of $200 \mathrm{~kg}$ urea/ha, but under oilpalm the highest production found at Burangrang under 4 years old oilpalm and application of $200 \mathrm{~kg}$ urea/ha, followed by several treatments which are unsignifican different.
\end{abstract}

Key words: Soybean, shade, $N$ dosage, soybean variety, and oilpalm

\begin{abstract}
ABSTRAK
Penelitian ini bertujuan untuk mempelajari perubahan karakter morfologi, komponen hasil beberapa varietas kedelai di bawah naungan tegakan kelapa sawit mengetahui varietas kedelai yang dapat tumbuh dan berproduksi lebih baik di bawah naungan tegakan kelapa sawit; dan mengetahui pengaruh pupuk urea terhadap pertumbuhan dan produksi kedelai di bawah naungan tegakan kelapa sawit. Penelitian dilaksanakan di Desa Ujung Labuan, Kabupaten Deli Serdang, Sumatera Utara, pada bulan Desember 2014-April 2015. Penelitian ini menggunakan Rancangan Petak-petak Terpisah (RPPT) yang terdiri dari 3 faktor dan 3 ulangan. Faktor pertama yaitu naungan: bawah tegakan
\end{abstract}


kelapa sawit umur 4 tahun, bawah tegakan kelapa sawit umur 6-7 tahun, areal terbuka; faktor kedua takaran pupuk urea: $200 \mathrm{~kg}$ urea/ha, $150 \mathrm{~kg}$ urea/ha, $100 \mathrm{~kg}$ urea/ha, dan 0 $\mathrm{kg}$ urea/ha; faktor ketiga varietas kedelai: Anjasmoro, Burangrang, dan Grobogan. Peubah yang diamati diantaranya tinggi tanaman, luas daun, bobot kering tanaman, produksi kedelai. Hasil penelitian menunjukkan pertumbuhan dan produksi kedelai dipengaruhi interaksi naungan, taraf $\mathrm{N}$ dan varietas kedelai. Pertumbuhan dan produksi kedelai lebih tinggi pada areal terbuka dengan pemberian $\mathrm{N}$ dan varietas yang dicobakan, kecuali untuk tinggi tanaman. Sedangkan pertumbuhan dan produksi kedelai pada bawah naungan tegakan kelapa sawit umur 4 tahun dan umur 6-7 tahun umumnya tidak berbeda nyata, namun jauh lebih rendah dibandingkan areal terbuka. Penggunaan taraf $\mathrm{N}$ pada naungan dan varietas juga berpengaruh nyata, dengan rataan pertumbuhan dan produksi tertinggi didapat dengan penggunaan $150 \mathrm{~kg}$ urea/ha. Produksi per hektar tertinggi dihasilkan varietas Burangrang pada areal terbuka pada pemberian $200 \mathrm{~kg}$ urea/ha, sedangkan bawah tegakan kelapa sawit tertinggi pada varietas Burangrang bawah tegakan kelapa sawit 4 tahun pada pemberian $200 \mathrm{~kg}$ urea/ha, diikuti beberapa perlakuan yang tidak berbeda nyata.

Key words: kacang kedelai, naungan, dosis N, varietas kedelai,kelapa sawit

\section{PENDAHULUAN}

Permintaan kedelai meningkat seiring dengan pertambahan jumlah penduduk, meningkatnya kesadaran akan bahan makanan bergizi dan berkembangnya berbagai industri makanan, sedangkan produksi dalam negeri baru mampu memenuhi 35-40\% kebutuhan. Sementara luas lahan pertanian potensial untuk tanaman kedelai semakin berkurang, sedangkan luasnya areal kelapa sawit yang ada saat ini menjadi potensi untuk penanaman kedelai di bawah tegakan kelapa sawit. Beberapa tanaman perkebunan dapat ditanam secara tumpangsari dengan tanaman pangan, hortikultura atau tanaman pohon. PC Jessykutty (2003) melakukan tumpangsari tanaman obat dengan tanaman kelapa sawit muda, sawit umur sedang dan umur tua.

Kendala menanam kedelai di bawah naungan tegakan kelapa sawit adalah intensitas cahaya matahari terhalang oleh tanaman kelapa sawit, gi, umur genjah, dan tahan/toleran terhadap cekaman biotik (hama dan penyakit) dan abiotik (lingkungan fisik). Upaya untuk meningkatkan produksi kedelai selain dengan penggunaan varietas unggul tahan naungan adalah penggunaan pupuk $\mathrm{N}$. Unsur nitrogen merupakan unsur yang diperlukan tanaman untuk pertumbuhan dan perkembangan daun di bawah naungan sehingga dapat tetap mencapai tingkat fotosintesis yang maksimal. Karena hal itu introduksi budidaya kedelai di perkebunan kelapa sawit perlu memperhitungkan kesesuaian varietas kedelai dengan tingkat naungan tajuk kelapa sawit, serta peningkatan kesuburan tanah melalui pemberian pupuk (Marwoto, dkk. 2012).

\section{BAHAN DAN METODE}

Penelitian dilaksanakan di Desa Ujung Labuan, Kabupaten Deli Serdang, Sumatera Utara, pada bulan Desember 2014-April 2015. Bahan yang digunakan adalah benih kedelai F2 dari Balitkabi 
selain itu terjadi kompetisi terhadap hara, air, dan lain sebagainya. Bila dibandingkan dengan tegakan karet, bahwa besarnya intensitas cahaya di bawah tegakan karet umur 2 tahun setara naungan paranet $25 \%$, umur 3 tahun setara paranet $50 \%$, dan umur 4 tahun melebihi naungan paranet $75 \%$ (Chozin et al. 1999). Sedangkan radiasi matahari optimum untuk fotosintesis kedelai pada kondisi laboratorium berkisar $0,3-0,8 \mathrm{kal} / \mathrm{cm}^{2} /$ menit (432$1152 \mathrm{kal} / \mathrm{cm}^{2} /$ hari) (Kassam, 1978). Nilai tersebut jauh lebih besar dibandingkan dengan intensitas cahaya di bawah tanaman karet.

Potensi hasil biji di lapangan dipengaruhi oleh interaksi antara faktor genetik varietas dengan pengelolaan kondisi lingkungan tumbuh. Varietas unggul memiliki sifat seperti hasil tingAnjasmoro, $\mathrm{V}_{2}=$ Varietas Burangrang, dan $\mathrm{V}_{3}=$ Varietas Grobogan .

Intensitas cahaya diukur dengan menggunakan Lux Tester diletakkan pada beberapa titik pada petak penanaman di pinggir maupun tengah petak penanaman pada beberapa periode waktu pagi hari (09.00-10.00 WIB), siang hari (12.00-13.00 WIB), dan sore hari (14.00-16.00 WIB).

Tanah diambil sebelum penanaman, secara acak dari beberapa titik dari permukaan tanah sampai sedalam 25-30 cm sebanyak masingmasing $1 \mathrm{~kg}$. Uji tanah dilakukan di Laboratorium Tanah BPTP Sumatera Utara. Persiapan lahan dilakukan dengan cara tanah dicangkul sedalam $30 \mathrm{~cm}$, dipecahkan menggunakan kored, diratakan. Dibuat petak-petak penanaman berukuran $2 \mathrm{~m} \times 2 \mathrm{~m}$ (di gawangan mati tegakan kelapa sawit $8 \mathrm{~m} \times 8 \mathrm{~m}$ x $8 \mathrm{~m})$. Diberikan kapur dolomit ( $\mathrm{CaO} 30 \%$, $\mathrm{MgO}$ 18-22\%) sebanyak 2,4 kg/petak, dan pupuk organik sebanyak $2,4 \mathrm{~kg} /$ petak.

Penanaman benih kedelai dilakukan
Malang, pupuk urea $(46 \% \mathrm{~N})$, pupuk $\mathrm{KCl}$, TSP, kapur dolomite super $(\mathrm{CaO}$ $30 \%, \mathrm{MgO} 18-22 \%$ ) dan pupuk organik granul prima, serta tanah bekas tanam kedelai. Alat yang digunakan adalah timbangan analitik, oven listrik, lux tekster, penggaris, cangkul, kored, tugal, dan lain-lain.

Penelitian ini menggunakan Rancangan Petak-petak Terpisah (RPPT) yang terdiri dari 3 (tiga) faktor. Adapun faktor penelitian tersebut dapat diuraikan sebagai berikut: Naungan (I) terdiri dari 3 (tiga) taraf: $\mathrm{I}_{0}=$ areal terbuka, $\mathrm{I}_{1}=$ bawah tegakan kelapa sawit umur 4 tahun, dan $\mathrm{I}_{2}=$ bawah tegakan kelapa sawit umur 6-7 tahun. Taraf urea $(\mathrm{N})$ terdiri dari 4 taraf: $\mathrm{N}_{3}=200 \mathrm{~kg}$ urea/ha), $\mathrm{N}_{2}=150 \mathrm{~kg}$ urea $/ \mathrm{ha}, \mathrm{N}_{1}=100 \mathrm{~kg}$ urea $/ \mathrm{ha}$, dan $\mathrm{N}_{0}=0 \mathrm{~kg}$ urea/ha. Varietas (V) terdiri dari 3 taraf: $\mathrm{V}_{1}=$ varietas

3. Bobot kering tanaman, diukur dengan cara mencabut 2 tanaman setiap petak, dilakukan pengeringan dengan menggunakan oven selama 2 x 24 jam pada suhu $60^{\circ} \mathrm{C}$, kemudian ditimbang dengan timbangan analitik.

4. Produksi per hektar diperoleh dengan mengonversikan produksi per plot.

Data hasil pengamatan dianalisis dengan sidik ragam pada taraf 5\%. Bila dalam pengujian sidik ragam diperoleh perlakuan yang berbeda nyata atau sangat nyata, maka dilakukan Uji Jarak Duncan Multiple Range Test (DNMRT) (Montgomery, 2001).

\section{HASIL DAN PEMBAHASAN}

\section{Tinggi tanaman $(\mathrm{cm})$}

Tabel 1 menunjukkan pengaruh interaksi bawah tegakan kelapa sawit (naungan), taraf $\mathrm{N}$ dan varietas ( $\mathrm{I} \times \mathrm{N} \mathrm{x}$ V) terhadap tinggi tanaman kedelai pada 70 HST. Pertumbuhan tinggi tanaman kedelai pada areal terbuka $\left(\mathrm{I}_{0}\right)$ lebih pendek dari pada bawah tegakan kelapa sawit dengan keempat taraf $\mathrm{N}$ yang 
dengan penugalan sedalam $1,5-2,0 \mathrm{~cm}$, setiap lubang diisi 2 (dua) benih kedelai yang sebelumnya dicampur dengan bakteri Rhizobium illetrysoy, serta tanah bekas tanam kedelai. Semua tanaman pada petak perlakuan diberi pupuk dasar TSP dan $\mathrm{KCl}$ bersamaan dengan waktu tanam, dosis $200 \mathrm{~kg}$ TSP $\mathrm{ha}^{-1}, 100 \mathrm{~kg} \mathrm{KCl} \mathrm{ha}{ }^{-1}$. Pupuk urea secara bertahap, setengah dosis sebagai starter bersamaan pemberian TSP dan $\mathrm{KCl}$, pemupukan susulan setengah dosis urea pada 20 - 30 HST atau bersamaan penyiangan.

Peubah yang diamati dalam penelitian ini diantaranya:

1. Tinggi tanaman diukur mulai dari pangkal batang sampai titik tumbuh.

2. Luas daun diukur dengan metoda gravimetri.

bawah tegakan kelapa sawit akan semakin tinggi dibanding dengan areal diberikan, terpendek pada varietas Grobogan $\left(\mathrm{V}_{3}\right)$ yang tidak ternaungi, pada semua taraf $\mathrm{N}$ tidak berbeda nyata. Hal ini sejalan dengan penelitian Titik Sundari dan Purwantoro (2014), yang melaporkan semakin tinggi tingkat naungan dari kanopi tanaman karet semakin rendah tingkat penerimaan cahaya oleh tanaman kedelai dibawah tegakan tanaman karet umur 3 dan 4 tahun, serta memperkecil diameter batang.

Tanaman kedelai tertinggi di bawah tegakan kelapa sawit 6-7 tahun $\left(\mathrm{I}_{2}\right)$ untuk varietas Burangrang $\left(\mathrm{V}_{2}\right)$ yang diberi pupuk urea $150 \mathrm{~kg} / \mathrm{ha}\left(\mathrm{N}_{2}\right)$. Tinggi tanaman kedelai kedua terbesar pada tegakan kelapa sawit 4 tahun $\left(\mathrm{I}_{1}\right)$ dengan $\mathrm{N}_{2}$. Semakin tinggi taraf pupuk urea yang diberikan maka tinggi tanaman kedelai di

terbuka.

Tabel 1. Pengaruh interaksi bawah tegakan kelapa sawit(naungan), taraf $\mathrm{N}$ dan varietas terhadap tinggi tanaman kedelai $(\mathrm{cm})$ pada 70 HST

\begin{tabular}{|c|c|c|c|c|}
\hline \multirow{2}{*}{ Naungan (I) } & \multirow{2}{*}{ Taraf N (N) } & \multicolumn{3}{|c|}{ Varietas } \\
\hline & & $\nabla_{1}$ & $\nabla_{2}$ & $\nabla_{3}$ \\
\hline \multirow{4}{*}{$\mathrm{I}_{0}$} & & & . $\mathrm{cm}$. . & \\
\hline & $\mathrm{N}_{0}$ & 76,63 e & $75,60 \mathrm{e}$ & $54,60 \mathrm{f}$ \\
\hline & $\mathbf{N}_{1}$ & $\begin{array}{l}4,51 \mathrm{e} \\
77,53 \mathrm{e}\end{array}$ & $76,54 \mathrm{e}$ & $\begin{array}{l}54,18 \mathrm{I} \\
53,90 \mathrm{f}\end{array}$ \\
\hline & $\mathrm{N}_{3}^{2}$ & 76,77 e & $83,20 \mathrm{de}$ & $55,84 \mathrm{f}$ \\
\hline \multirow[t]{4}{*}{$\mathrm{I}_{1}$} & $\mathrm{~N}_{0}$ & $84,13 \mathrm{~d}$ & $83,28 \mathrm{de}$ & $77,20 \mathrm{e}$ \\
\hline & $\mathrm{N}_{1}$ & $88,80 \mathrm{~cd}$ & $83,86 \mathrm{~d}$ & $80,74 \mathrm{de}$ \\
\hline & $\mathrm{N}_{2}$ & $94,90 \mathrm{~b}$ & $93,13 b c$ & $90,33 \mathrm{c}$ \\
\hline & $\mathrm{N}_{3}$ & $92,44 \mathrm{bc}$ & $87,72 \mathrm{~cd}$ & $91,59 \mathrm{bc}$ \\
\hline \multirow[t]{4}{*}{$\mathrm{I}_{2}$} & $N_{0}$ & $85,18 \mathrm{~d}$ & $91,17 \mathrm{bc}$ & $78,43 \mathrm{e}$ \\
\hline & $\mathrm{N}_{1}$ & $85,33 \mathrm{~d}$ & $93,14 b c$ & 78,24 e \\
\hline & $\mathrm{N}_{2}$ & $88,88 \mathrm{~cd}$ & $99,50 \mathrm{a}$ & $80,82 \mathrm{de}$ \\
\hline & $\mathrm{N}_{3}$ & $93,26 \mathrm{bc}$ & $102,28 \mathrm{a}$ & $85,58 \mathrm{~cd}$ \\
\hline
\end{tabular}

Keterangan: Notasi huruf yang berbeda pada kolom atau baris menunjukkan perbedaan yang nyata pada taraf 5\% menurut uji jarak Duncan

\section{Luas Daun}

Luas daun tiga varietas kedelai pada tiga naungan dan empat taraf $\mathrm{N}$ dapat dilihat pada Tabel 2. Dari Tabel 2 dapat dilihat luas daun tanaman kedelai di areal terbuka $\left(\mathrm{I}_{0}\right)$ lebih tinggi dibanding bawah tegakan kelapa sawit untuk semua varietas yang digunakan dan jumlah $\mathrm{N}$ yang diberikan. Luas daun tertinggi diperoleh pada $\mathrm{I}_{0} \mathrm{~N}_{3} \mathrm{~V}_{2}$. 
Tabel 2. Pengaruh interaksi bawah tegakan kelapa sawit (naungan), taraf $\mathrm{N}$ dan varietas terhadap luas daun tanaman kedelai pada 70 HST

\begin{tabular}{|c|c|c|c|c|}
\hline \multirow{2}{*}{ I } & \multirow{2}{*}{$\mathrm{N}$} & \multicolumn{3}{|c|}{ Varietas } \\
\hline & & $\mathrm{V}_{1}$ & $\mathrm{~V}_{2}$ & $\mathrm{~V}_{3}$ \\
\hline \multirow{5}{*}{$\mathrm{I}_{0}$} & & & $\ldots . \mathrm{cm}^{2}$. & \\
\hline & $\mathrm{N}_{0}$ & $1.467 \mathrm{~d}$ & $1.656 \mathrm{c}$ & $1.238 \mathrm{e}$ \\
\hline & $\mathrm{N}_{1}$ & $1.721 \mathrm{c}$ & $1.718 \mathrm{c}$ & $1.309 \mathrm{e}$ \\
\hline & $\mathrm{N}_{2}$ & $2.097 \mathrm{a}$ & $1.856 \mathrm{~b}$ & $1.462 \mathrm{~d}$ \\
\hline & $\mathrm{N}_{3}$ & $1.925 \mathrm{~b}$ & $2.063 \mathrm{a}$ & $1.424 \mathrm{~d}$ \\
\hline \multirow[t]{4}{*}{$\mathrm{I}_{1}$} & $\mathrm{~N}_{0}$ & $401 \mathrm{~g}$ & $405 \mathrm{~g}$ & $402 \mathrm{~g}$ \\
\hline & $\mathrm{N}_{1}$ & $416 \mathrm{~g}$ & $445 \mathrm{fg}$ & $411 \mathrm{~g}$ \\
\hline & $\mathrm{N}_{2}$ & $501 \mathrm{fg}$ & $499 \mathrm{fg}$ & $448 \mathrm{fg}$ \\
\hline & $\mathrm{N}_{3}$ & $455 \mathrm{fg}$ & $486 \mathrm{fg}$ & $443 \mathrm{fg}$ \\
\hline \multirow[t]{4}{*}{$\mathrm{I}_{2}$} & $\mathrm{~N}_{0}$ & $412 \mathrm{~g}$ & $382 \mathrm{~g}$ & $409 \mathrm{~g}$ \\
\hline & $\mathrm{N}_{1}$ & $426 \mathrm{~g}$ & $430 \mathrm{~g}$ & $424 \mathrm{~g}$ \\
\hline & $\mathrm{N}_{2}$ & $508 \mathrm{fg}$ & $518 \mathrm{f}$ & $508 \mathrm{f}$ \\
\hline & $\mathrm{N}_{3}$ & $490 \mathrm{fg}$ & $503 \mathrm{fg}$ & $497 \mathrm{fg}$ \\
\hline
\end{tabular}

Keterangan : Notasi huruf yang berbeda pada kolom atau baris menunjukkan perbedaan yang nyata pada taraf 5\% menurut uji jarak Duncan

Daun tanaman kedelai pada bawah tegakan kelapa sawit mengalami penurunan luas. Blum (1979) mengaitkan umur genjah dengan luas daun yang lebih kecil. Namun pada penelitian ini luas daun tidak berbeda nyata pada ketiga varietas yang dicobakan pada $\mathrm{I}_{1}$ dan $\mathrm{I}_{2}$. Tipisnya daun Bobot Kering Tanaman

Bobot kering tanaman kedelai dengan perlakuan naungan dan taraf $\mathrm{N}$ disajikan pada Tabel 3. Pada Tabel 3, bobot kering tanaman kedelai tertinggi diperoleh pada areal terbuka $\left(\mathrm{I}_{0}\right)$ pada pemberian $150 \mathrm{~kg}$ Urea/ha $\left(\mathrm{N}_{2}\right)$. Sedangkan di bawah tegakan kelapa varietas Anjasmoro (pengamatan lapang, tanpa data) pada $\mathrm{I}_{1}-\mathrm{I}_{2}$ mengakibatkan varietas Anjasmoro lebih rentan mengalami kerusakan dibanding dua varietas lainnya.

Luas daun bawah tegakan kelapa sawit tertinggi diperoleh pada pemberian $\mathrm{N}_{2}$ pada ketiga varietas yang digunakan.

sawit pada perlakuan $\mathrm{N}_{2}$ dan $\mathrm{N}_{3}$ tidak berbeda nyata. Produksi terendah diperoleh pada perlakuan $\mathrm{I}_{1} \mathrm{~N}_{0}$ dan $\mathrm{I}_{2} \mathrm{~N}_{0}$. Semakin tinggi taraf pupuk urea yang diberikan maka luas daun tanaman kedelai semakin tinggi di areal terbuka dibanding yang ternaungi kelapa sawit.

Tabel 3. Pengaruh interaksi bawah tegakan kelapa sawit (naungan) dan taraf $\mathrm{N}$ terhadap bobot kering tanaman kedelai pada 70 HST

\begin{tabular}{|c|c|c|c|c|}
\hline \multirow{2}{*}{ Naungan } & \multicolumn{4}{|c|}{ Taraf N } \\
\hline & $\mathrm{N}_{0}$ & $\mathrm{~N}_{1}$ & $\mathrm{~N}_{2}$ & $\mathrm{~N}_{3}$ \\
\hline & $\cdots$ & ...... & ......... & ......... \\
\hline $\mathrm{I}_{0}$ & $37,83 \mathrm{~d}$ & $39,58 \mathrm{c}$ & $42,91 \mathrm{a}$ & $42,20 \mathrm{~b}$ \\
\hline $\mathrm{I}_{1}$ & $8,00 \mathrm{f}$ & 8,46 ef & $8,86 \mathrm{e}$ & $8,77 \mathrm{e}$ \\
\hline $\mathrm{I}_{2}$ & $8,00 \mathrm{f}$ & 8,50 ef & $8,94 \mathrm{e}$ & 8,88 e \\
\hline
\end{tabular}

Keterangan : Notasi huruf yang berbeda pada kolom atau baris menunjukkan perbedaan yang nyata pada taraf 5\% menurut uji jarak Duncan

Semakin tinggi taraf pupuk urea yang diberikan bobot kering tanaman kedelai semakin tinggi di areal terbuka dan yang ternaungi kelapa sawit. Pemberian $150 \mathrm{~kg}$ Urea/ha $\left(\mathrm{N}_{2}\right)$ pada $\mathrm{I}_{1}$ dan $\mathrm{I}_{2}$ menghasilkan bobot kering nutrisi dan lingkungan cukup tersedia dan berimbang untuk diserap oleh tanaman. Bahkan kondisi adanya faktor pembatas maka $\mathrm{N}$ dibutuhkan untuk mendukung pertumbuhan tanaman melalui rubisco, menyokong 
tanaman kedelai tertinggi. Hal ini menunjukkan pemberian $\mathrm{N}_{2}$ sudah mencukupi kebutuhan tanaman. Selanjutnya Dwijoseputro (2000) menerangkan bahwa suatu tanaman akan tumbuh dengan subur bila kebutuhan pertumbuhan tanaman menjadi lebih baik (Makino et al., 1999).

Bobot kering tanaman kedelai oleh pengaruh interaksi naungan dan varietas (I x V) disajikan pada Tabel 4.

Tabel 4. Pengaruh interaksi bawah tegakan kelapa sawit (naungan) dan varietas terhadap bobot kering tanaman kedelai pada 70 HST

\begin{tabular}{|c|c|c|c|}
\hline \multirow{2}{*}{ Naungan } & \multicolumn{3}{|c|}{ Varietas } \\
\hline & $\mathrm{V}_{1}$ & $\mathrm{~V}_{2}$ & $\mathrm{~V}_{3}$ \\
\hline & & .......g...... & ……........ \\
\hline $\mathrm{I}_{0}$ & $42,93 \mathrm{~b}$ & $44,67 \mathrm{a}$ & $34,30 \mathrm{c}$ \\
\hline $\mathrm{I}_{1}$ & $8,58 \mathrm{~d}$ & $8,56 \mathrm{~d}$ & $8,58 \mathrm{~d}$ \\
\hline $\mathrm{I}_{2}$ & $8,45 \mathrm{~d}$ & $8,59 \mathrm{~d}$ & $8,52 \mathrm{~d}$ \\
\hline
\end{tabular}

Keterangan : Notasi huruf yang berbeda pada kolom atau baris menunjukkan perbedaan yang nyata pada taraf 5\% menurut uji jarak Duncan

Tabel 4 memperlihatkan bobot kering tanaman kedelai tertinggi diperoleh pada areal tanpa naungan $\left(\mathrm{I}_{0}\right)$ pada varietas Burangrang $\left(\mathrm{V}_{2}\right)$. Pertumbuhan antara varietas kedelai pada areal terbuka berbeda untuk bobot

bahwa tanaman pada hakekatnya merupakan konstitusi genetik dan lingkungan. Adapun pertumbuhan dan produksi tanaman dipengaruhi oleh proses fotosintesis pada tanaman sebagaimana disampaikan Malcom (1992). Hasil pada penelitian ini bahwa bobot kering tanaman $\left(\mathrm{I}_{1}-\mathrm{I}_{2}\right) \quad \mathrm{X}$ $\left(\mathrm{V}_{1} \mathrm{~V}_{2} \mathrm{~V}_{3}\right)$ hanya $19,23-25,01 \%$ dari $\mathrm{I}_{0} \mathrm{~V}$, hal ini

\section{Produksi per Hektar}

Produksi per hektar dengan naungan, taraf $\mathrm{N}$ dan varietas berbeda kering tanaman, sedangkan pada tegakan kelapa sawit tidak berbeda nyata pada semua varietas yang digunakan. Jadi pada kondisi ling-kungan yang berbeda akan terjadi perbedaan respon setiap varietas. Menurut Sitompul, dkk (1995) i

disebabkan oleh intensitas cahaya yang diteruskan tajuk kelapa sawit yang sampai ke permukaan tanah di bawahnya rendah (27-30\%). Sihar (2004) dengan penanaman menggunakan polibag menyatakan, tingkat persentase naungan 20-40\% masih sesuai untuk pertumbuhan dan produksi kedelai di bawah kanopi tanaman.

(I x N) disajikan pada Tabel 5. 
Tabel 5. Produksi per hektar tiga varietas kedelai pada tiga areal naungan dan empat taraf $\mathrm{N}$

\begin{tabular}{|c|c|c|c|c|}
\hline \multirow{2}{*}{ Naungan } & \multirow{2}{*}{ Taraf $\mathrm{N}$} & \multicolumn{3}{|c|}{ Varietas } \\
\hline & & $\mathrm{V}_{1}$ & $\mathrm{~V}_{2}$ & $\mathrm{~V}_{3}$ \\
\hline \multirow{5}{*}{$\mathrm{I}_{0}$} & & & & \\
\hline & $\mathrm{N}_{0}$ & $2,11 \mathrm{i}$ & $2,50 \mathrm{~g}$ & $2,18 \mathrm{hi}$ \\
\hline & $\mathrm{N}_{1}$ & $2,64 \mathrm{f}$ & $2,89 \mathrm{e}$ & $2,30 \mathrm{~h}$ \\
\hline & $\mathrm{N}_{2}$ & $3,62 \mathrm{~b}$ & $3,46 \mathrm{c}$ & $3,43 \mathrm{c}$ \\
\hline & $\mathrm{N}_{3}$ & $3,06 \mathrm{~d}$ & $3,70 \mathrm{a}$ & $3,14 \mathrm{~d}$ \\
\hline \multirow[t]{4}{*}{$\mathrm{I}_{1}$} & $\mathrm{~N}_{0}$ & $0,23 \mathrm{n}$ & $0,22 \mathrm{n}$ & $0,23 \mathrm{n}$ \\
\hline & $\mathrm{N}_{1}$ & $0,32 \mathrm{mn}$ & $0,36 \mathrm{~m}$ & $0,30 \mathrm{mn}$ \\
\hline & $\mathrm{N}_{2}$ & $0,50 \mathrm{kl}$ & $0,58 \mathrm{jk}$ & $0,54 \mathrm{k}$ \\
\hline & $\mathrm{N}_{3}$ & 0,461 & $0,64 \mathrm{j}$ & 0,451 \\
\hline \multirow[t]{4}{*}{$\mathrm{I}_{2}$} & $\mathrm{~N}_{0}$ & $0,30 \mathrm{mn}$ & $0,26 \mathrm{n}$ & $0,26 \mathrm{n}$ \\
\hline & $\mathrm{N}_{1}$ & $0,37 \mathrm{~m}$ & $0,33 \mathrm{mn}$ & $0,33 \mathrm{mn}$ \\
\hline & $\mathrm{N}_{2}$ & $0,55 \mathrm{k}$ & $0,57 \mathrm{jk}$ & $0,54 \mathrm{k}$ \\
\hline & $\mathrm{N}_{3}$ & $0,51 \mathrm{kl}$ & $0,60 \mathrm{jk}$ & $0,52 \mathrm{kl}$ \\
\hline
\end{tabular}

Keterangan : Notasi huruf yang berbeda pada kolom atau baris menunjukkan perbedaan yang nyata pada taraf $5 \%$ menurut uji jarak Duncan

Dari Tabel 5, produksi per hektar tertinggi dihasilkan $\mathrm{I}_{0} \mathrm{~N}_{3} \mathrm{~V}_{2}$. Produksi tertinggi bawah tegakan kelapa sawit dihasilkan $\mathrm{I}_{1} \mathrm{~N}_{3} \mathrm{~V}_{2}(0,64 \mathrm{t} / \mathrm{ha})$, diikuti beberapa perlakuan yang tidak berbeda nyata antara $\mathrm{I}_{2} \mathrm{~N}_{3} \mathrm{~V}_{2}(0,60 \mathrm{t} / \mathrm{ha}), \mathrm{I}_{2} \mathrm{~N}_{2} \mathrm{~V}_{2}$ (0,57 t/ha), dan $\mathrm{I}_{1} \mathrm{~N}_{2} \mathrm{~V}_{2}(0,58 \mathrm{t} / \mathrm{ha})$.

\section{SIMPULAN}

Penanaman kedelai di bawah tegakan kelapa sawit umur 4 tahun dan 6 tahun mendapatkan cekaman naungan yang ekstrem yang lebih besar dari $60 \%$, sehingga produksi ketiga varietas kedelai dengan pemberian empat taraf $\mathrm{N}$ masih $18,38 \%$ dari produksi kedelai pada tanpa naungan.

Dwijoseputro, D. 2000. Pengantar Fisiologi Tumbuhan. Gramedia, Jakarta. 232 hlm.

Kassam, A.H. 1978. Agro Climatic Suitability Assesment of Rainfed Crops in African by Growing Period Zones. FAO. Rome.

Makino, A., Hiromi, N., and Tadahiko, M. 1999. Photosynthesis, Plant Growth and $\mathrm{N}$ Allocation in Transgenic Rice Plants With Decreased Rubisco Under CO2 Enrichment. Journal of Experiment of Botany. Vol 51. p.

\section{DAFTAR PUSTAKA}

Blum, A. 1979. Genetic Improvement of Drought Resistance in Crops Plants: A Case for Sorghum. p.429445. dalam H. Mussel and R.S. Staples (eds.). Stres Physiology in Crop Plants. Wiley Internat. New York.

Chozin, M.A., Sopandie, D. Sastrosumarjo dan S. Suwarno. 1999. Physiology and Genetic of Upland Rice Adaptation to Shade. (Laporan Graduate Team Research Grant, Proyek URGE). Jakarta. Direktorat Jenderal Pendidikan Tinggi.

P.C. Jessykutty. 2003. Techno Economy Study on Intercropping Medicinal Plants in Oil Palm Plantations. Thesis. Faculty of Agriculture. Kerala Agricultural University. Thrissur.

Sihar, S. 2004. Pengaruh Pemberian Naungan Terhadap Pertumbuhan dan Produksi Beberapa Varietas Kedelai (Glycine max L. Merril) di Polibeg. Tesis. Program Pascasarjana USU. Medan.

Sitompul, S.M. and Guritno. 1995. Analisis Pertumbuhan Tanaman. 
383-389.

Malcom, B. and Wilkins. 1992. Fisiologi Tanaman. Penerjemah Mul Mulyani Sutejo dan A. G Kartasapoetra. Bumi Aksara. Jakarta. Hal.430-432.

Marwoto, A. Taufiq dan Suyamto. 2012. Potensi Pengembangan Tanaman Kedelai di Perkebunan Kelapa Sawit. Badan Penelitian dan Pengembangan Pertanian. Jawa Timur.
Gadjah Mada University Press. Yogjakarta.

Sundari, T. dan Purwantoro. 2014. Kesesuaian Genotipe Kedelai untuk Tanaman Sela di Bawah Tegakan Pohon Karet. Balai Penelitian Tanaman Aneka Kacang dan Umbi. Malang. Penelitian Pertanian Tanaman Pangan. 33 (1). 9 hal. 